\title{
Synthesis, crystallographic characterization, DFT and TD-DFT studies of Oxyma-sulfonate esters
}

\author{
SAIED M SOLIMAN ${ }^{\mathrm{a}, \mathrm{b}, *}$, HAZEM A GHABBOUR ${ }^{\mathrm{c}, \mathrm{d}}$, SHERINE N KHATTAB $^{\mathrm{b}}$, \\ MOHAMMED R H SIDDIQUI ${ }^{\mathrm{e}}$ and AYMAN EL-FAHAM ${ }^{\mathrm{b}, \mathrm{e}, *}$ \\ ${ }^{a}$ Department of Chemistry, Rabigh College of Science and Art, King Abdulaziz University, P.O. Box 344, \\ Rabigh 21911, Saudi Arabia \\ ${ }^{b}$ Department of Chemistry, Faculty of Science, Alexandria University, P.O. Box 426, Ibrahimia, Alexandria \\ 21321, Egypt \\ ${ }^{\mathrm{c}}$ Department of Pharmaceutical Chemistry, College of Pharmacy, King Saud University, Riyadh 11451, Saudi \\ Arabia \\ ${ }^{\mathrm{d}}$ Department of Medicinal Chemistry, Faculty of Pharmacy, University of Mansoura, Mansoura 35516, Egypt \\ e Department of Chemistry, College of Science, King Saud University, P. O. Box 2455, Riyadh 11451, Saudi \\ Arabia \\ E-mail: Saied1soliman@yahoo.com; aymanel_faham@hotmail.com
}

MS received 8 March 2017; revised 19 June 2017; accepted 7 July 2017; published online 29 August 2017

\begin{abstract}
Three oxyma sulfonate esters were prepared using dichloromethane-water (two-phase method) in the presence of sodium carbonate for scavenging $\mathrm{HCl}$. The products were characterized by FT-IR, NMR $\left({ }^{1} \mathrm{H}\right.$ and ${ }^{13} \mathrm{C}$ ), UV-Vis spectra and elemental analysis. X-ray single crystal diffraction experiments proved the molecular structures of three esters. Their molecular structures were also calculated using DFT/B3LYP method. The optimized structures agreed well with the X-ray structures. Time-dependent density functional theory (TDDFT) was used to assign the electronic absorption bands observed experimentally. Pyridine derivative showed two bands at shorter $\lambda_{\max }$ compared to the others, both experimentally and theoretically. The NMR chemical shifts were computed for protons and carbons using GIAO method, which correlated well with the experimental data. Natural charges, dipole moments and chemical reactivity of these molecules, as well as their non-linear optical activity, were computed and compared.
\end{abstract}

Keywords. Oxyma; sulfonate ester; X-ray crystallography; TD-DFT; NLO; NBO.

\section{Introduction}

Sulfonate esters are considered as important precursors for the synthesis of sulfonamides, which exhibit a wide range of biological activities. ${ }^{1,2}$ The differences in their reactivity have been exploited in selective sulfonamide formation. ${ }^{3}$ A comprehensive literature survey of the synthesis of sulfonamides revealed several synthetic strategies, which includes the methods for activation of the sulfonic acids to the corresponding 3-methylimidazoliumtriflates, ${ }^{4}$ pentafluorophenolates, ${ }^{5}$ sulfonyl benzotriazoles, ${ }^{6} \quad p$-nitrophenolate esters, ${ }^{7}$ and trichlorophenolates. ${ }^{8}$ However, all the reported methods need either prolonged heating con-

\footnotetext{
*For correspondence
}

ditions or severe conditions such as using trifluoromethanesulfonic anhydride (TfO). Recently milder and more efficient method for the synthesis of sulfonamide by activating sulfonic acid group to the corresponding sulfonate ester of the ethyl 2-cyano2-(hydroxyimino)acetate (Oxyma, 1; Figure 1) was reported. ${ }^{3}$

Sulfonate ester of 1-hydroxybenzotriazole (HOBt 2) derivatives has been synthesized and used for peptide coupling. ${ }^{9,10}$ The reactivity of these sulfonate esters was affected by the presence of electron-withdrawing substituent in both the benzotriazole and the sulfonic acid moieties. ${ }^{11-14}$ Later, 7-Aza-1-hydroxybenzotriazole (HOAt 3)has been reported to be more efficient than HOBt 2 due to the electronic effect caused by the pyridine ring. ${ }^{15,16}$ Because of the explosive report of HOBt 3 
<smiles>CCOC(=O)/C(C#N)=N\O</smiles>

Oxyma; 1<smiles>[X]c1cccc2nnn(O)c12</smiles>

$\mathrm{X}=\mathrm{CH}, \mathrm{HOBt} ; 2$

$\mathrm{X}=\mathrm{N}$, HOAt; 3
Figure 1. Structure of oxyma and benzotriazole derivatives.

and its derivatives, ${ }^{17}$ ethyl 2-cyano-2-(hydroxyimino) acetate (Oxyma, 1) has been used as a potential replacement for both HOBt and HOAt (Figure 1). ${ }^{18,19}$

Recently, $N$-alkyl-cyanoacetamido oximes 4-7, ${ }^{20-22}$ $\mathrm{N}$-hydroxybenzimidoyl cyanide $\mathbf{8}$, and $\mathrm{N}$ hydroxypicolinimidoyl cyanide 9 (Figure 2), were reported and used for the preparation of sulfonate esters. The sulfonate esters 10-15 of the oximes shown in Figure 3 were evaluated for their anti-proliferation effect on the mouse fibroblast L929. The analysis showed that these compounds (10-15) have growth inhibition activity on L929 cells. ${ }^{20}$

Herein, we report a modified method for the synthesis of the sulfonate esters using dichloromethanewater (two-phase method) in the presence of sodium carbonate for the scavenging of the $\mathrm{HCl}$. X-ray crystallography was used to determine the structures of the three prepared sulfonate esters. Time dependent density functional theory (TD-DFT) was used to assign their electronic spectra. The natural bond orbital analysis was performed to analyze the charge distributions and to study the different intramolecular charge transfer within the studied systems.

\section{Experimental}

\subsection{Materials and methods}

Melting points were determined with a Mel-Temp apparatus (Chemie GmbH, 82024 Taufkirchen, Germany). Nuclear magnetic resonance spectra $\left({ }^{1} \mathrm{H}\right.$ NMR and ${ }^{13} \mathrm{C}$ NMR spectra) were recorded on a JEOL ECP-400 MHz spectrometer (JEOL Ltd., Tokyo, Japan) using $\mathrm{CDCl}_{3}$ or DMSO-d $\mathrm{d}_{6}$ as solvent and reported in $\delta$-units (Figures S1-S3, Supplementary data). Fourier transform infrared spectroscopy (FT-IR) spectra were recorded on Nicolet 6700 spectrometer (Thermo Scientific, Fishers, IN, USA) using $\mathrm{KBr}$ discs. Elemental analyses were performed on Perkin-Elmer 2400 elemental analyzer (Perkin Elmer Inc.,Waltham, MA USA). The solvents used were of HPLC reagent grade and all the chemicals were purchased from Sigma-Aldrich (Steinheim, Germany), Fluka (Steinheim, Germany). The reactions and the purity of the compounds were followed by TLC on silica gel-protected aluminum sheets (Type 60 GF254, Merck Millipore, Billerica, MA, USA) using UV lamp for spot visualization. The electronic spectra of the studied compounds were measured in different solvents such as acetonitrile, methanol and dichloromethane using UV-Vis spectroscopy (Perkin Elmer Lambda 35; Waltham, MA, USA).

\subsection{General method for the synthesis of oxyma derivative}

The two oximes 8 and 9 were synthesized according to the previously reported method ${ }^{20}$ and used for the preparation of the sulfonate esters $\mathbf{1 1}, \mathbf{1 4}$ and $\mathbf{1 6} .^{20}$

\section{2a General method for the synthesis of sulfonate} esters: The reported method ${ }^{20}$ was modified as follows: To a solution of $5 \mathrm{mmol}$ of oxime $8(0.73 \mathrm{~g})$ or $9(0.735 \mathrm{~g})$ and $\mathrm{Na}_{2} \mathrm{CO}_{3}(0.5 \mathrm{~g}, 5 \mathrm{mmol})$ in $30 \mathrm{~mL}$ of dichloromethane (DCM)-water (1:1), 4-tosyl chloride $\mathbf{1 8 a}(0.9 \mathrm{~g}, 5 \mathrm{mmol})$ or 2naphthalene sulfonyl chloride $\mathbf{1 8 b}(1.135 \mathrm{~g}, 5 \mathrm{mmol})$ in $15 \mathrm{~mL}$ of dichloromethane was added dropwise at $0^{\circ} \mathrm{C}$. The reaction mixture was stirred at $0^{\circ} \mathrm{C}$ for $1 \mathrm{~h}$ and then at room temperature for $4 \mathrm{~h}$. After completion of the reaction as monitored by TLC (ethylacetate-hexane; 4:6), $50 \mathrm{~mL}$ of $\mathrm{CH}_{2} \mathrm{Cl}_{2}$ was added, and the organic layer was collected and washed with water $(20 \mathrm{~mL})$ andsaturated aqueous $\mathrm{NaCl}(20 \mathrm{~mL})$. It was finally dried over $\mathrm{Na}_{2} \mathrm{SO}_{4}$ anhydrous. After removal of the solvent under reduced pressure, the residue was recrystallized from $\mathrm{CH}_{2} \mathrm{Cl}_{2}$-hexane to give the sulfonate esters in their crystallized form.<smiles>[X]CCN(CC)C(=O)/C(C#N)=N\O</smiles>

$\mathrm{X}=\mathrm{O} ; 4$ $\mathrm{X}=\mathrm{CH}_{2} ; 5$<smiles>[R]N([R])C(=O)/C(C#N)=N/O</smiles>

$\mathrm{R}^{1}=\mathrm{R}^{2}=\mathrm{H} ; 6$ $\mathrm{R}^{1}=\mathrm{C}_{2} \mathrm{H}_{5}, \mathrm{R}^{2}=\mathrm{H} ; 7$<smiles>[X]c1ccccc1/C(C#N)=N/O</smiles>

$$
\mathrm{X}=\mathrm{CH} ; 8
$$$$
\mathrm{X}=\mathrm{N} ; 9
$$

Figure 2. Structure of $N$-alkyl-cyanoacetamidooximes 4-7, $N$-hydroxybenzimidoyl cyanide $\mathbf{8}$, and $N$-hydroxypicolinimidoyl cyanide, $\mathbf{9}$. 
<smiles>Cc1ccc(S(=O)(=O)O/N=C(/C#N)C(=O)N2CCCCC2)cc1</smiles>

10<smiles>N#C/C(=N/OS(=O)(=O)c1ccc2ccccc2c1)C(N)=O</smiles>

13<smiles>Cc1ccc(S(=O)(=O)O/N=C(\C#N)c2ccccc2)cc1</smiles>

11<smiles>N#C/C(=N/OS(=O)(=O)c1ccc2ccccc2c1)c1ccccc1</smiles>

14<smiles>N#C/C(=N/OS(=O)(=O)c1ccc2ccccc2c1)C(=O)N1CCCCC1</smiles>

12<smiles>N#C/C(=N/OS(=O)(=O)c1ccc2ccccc2c1)c1ccccn1</smiles>

15

Figure 3. Structure of 4-tosyl esters 10, 11 and 2-naphthalenesulfonyl esters 12-15.

2.2b N-(tosyloxy)benzimidoyl cyanide (11): The product was obtained as white crystals, in $84 \%$ yield, M.p.: $112^{\circ} \mathrm{C}$; $\left[\mathrm{Lit}^{20} 85 \%\right.$ yield, M.p.: $\left.110-111^{\circ} \mathrm{C}\right]$; IR $\left(\mathrm{KB}^{\mathrm{r},} \nu / \mathrm{cm}^{-1}\right)$ : $2242(\mathrm{CN}), 1393,1187\left(\mathrm{SO}_{2}\right.$, sulf ${ }^{\text {on }}$ ate). ${ }^{1} \mathrm{H}$ NMR (400 $\left.\mathrm{MHz}, \mathrm{CDCl}_{3}\right)$ ppm: $\delta 2.45\left(3^{\mathrm{H}}, \mathrm{s}, \mathrm{CH}_{3}\right), 7.39(2 \mathrm{H}, \mathrm{d}, \mathrm{Ar}-$ $\mathrm{H}, J=8.8 \mathrm{~Hz}), 7.46(3 \mathrm{H}, \mathrm{t}, \operatorname{Ar}-\mathrm{H}), 7.57(1 \mathrm{H}, \mathrm{t}, \operatorname{Ar}-\mathrm{H}$, $J=7.3 \mathrm{~Hz}), 7.78(2 \mathrm{H}, \mathrm{d}, \mathrm{Ar}-\mathrm{H}, J=8.0 \mathrm{~Hz}), 7.94(1 \mathrm{H}$, $\mathrm{d}, \mathrm{Ar}-\mathrm{H}, J=8.0 \mathrm{~Hz}) \cdot{ }^{13} \mathrm{C}$ NMR $\left(100 \mathrm{MHz}, \mathrm{CDCl}_{3}\right) \mathrm{ppm}$ : $\delta 21.8,107.7,127.3,127.5,129.3,129.4,130.2,131.2,133.5$, 139.4, 146.5. Anal. Calcd. for $\mathrm{C}_{15} \mathrm{H}_{12} \mathrm{~N}_{2} \mathrm{O}_{3} \mathrm{~S}$ : C, 59.99; $H, 4.03 ; N, 9.33 \%$. Fo $\mathrm{u}_{n} \mathrm{~d}$ : C, 60.16; H, 4.25; N, 9.05\%.

\section{2c N-(naphthalen-2-ylsulfonyloxy)benzimidoyl} cyanide (14): The product was obtained as white crystals in $88 \%$ yield, M.p.: $134-135^{\circ} \mathrm{C}$; [ $\mathrm{Lit}^{20}$ yield $86 \%$, M.p.:133$\left.134^{\circ} \mathrm{C}\right] \mathrm{IR}\left(\mathrm{KBr}, v / \mathrm{cm}^{-1}\right): 2234(\mathrm{CN}), 1390,1186\left(\mathrm{SO}_{2}\right.$, sulfonate). ${ }^{1} \mathrm{HNMR}\left(400 \mathrm{MHz}, \mathrm{CDCl}_{3}\right) \mathrm{ppm}: \delta 7.44(2 \mathrm{H}, \mathrm{t}$, Ar- $\mathrm{H}, J=8.1 \mathrm{~Hz}), 7.54(1 \mathrm{H}, \mathrm{t}, \mathrm{Ar}-\mathrm{H}, J=7.3 \mathrm{~Hz}), 7.65-$ $7.78(4 \mathrm{H}, \mathrm{m}, \mathrm{Ar}-\mathrm{H}), 7.93-8.04(4 \mathrm{H}, \mathrm{m}, \mathrm{Ar}-\mathrm{H}), 8.65(1 \mathrm{H}, \mathrm{s}$, Ar-H). ${ }^{13}$ CNMR (100 MHz, $\left.\mathrm{CDCl}_{3}\right)$ ppm: $\delta$ 107.6, 123.1, 127.1, 127.5, 128.1, 129.3, 129.6, 129.7, 130.0, 131.0, 131.6, 131.9, 133.4, 135.8, 139.5. Anal. Calcd. for $\mathrm{C}_{18} \mathrm{H}_{12} \mathrm{~N}_{2} \mathrm{O}_{3} \mathrm{~S}$ : C, 64.27; H, 3.60; N, 8.33\%. Found: C, 64.11; H, 3.35; N, $8.05 \%$.

2.2d N-(tosyloxy)picolinimidoyl cyanide (16): The product was obtained as grey crystals, in $88 \%$ yield, M.p.: 129-130 ${ }^{\circ}$; IR $\left(\mathrm{KBr}, \nu / \mathrm{cm}^{-1}\right): 2247(\mathrm{CN}), 1394,1173$ ( $\mathrm{SO}_{2}$, sulfonate). ${ }^{1} \mathrm{H}$ NMR (400 $\mathrm{MHz}, \mathrm{CDCl}_{3}$ ) ppm: $\delta 2.46$ $\left(3 \mathrm{H}, \mathrm{s}, \mathrm{CH}_{3}\right), 7.39-7.47(3 \mathrm{H}, \mathrm{m}, \mathrm{Ar}-\mathrm{H}), 7.78-7.95(4 \mathrm{H}, \mathrm{m}$, $\mathrm{Ar}-\mathrm{H}), 8.72(1 \mathrm{H}, \mathrm{d}, \mathrm{Ar}-\mathrm{H}, J=4.4 \mathrm{~Hz}) \cdot{ }^{13} \mathrm{CNMR}(100$ $\mathrm{MHz}, \mathrm{CDCl}_{3}$ ) ppm: $\delta 21.9,107.4,121.7,126.9$. 129.3, 130.2, 130.9, 137.3, 140.1, 146.8, 146.9, 150.4. Anal. Calcd. for $\mathrm{C}_{14} \mathrm{H}_{11} \mathrm{~N}_{3} \mathrm{O}_{3} \mathrm{~S}$ : C, 55.80; H, 3.68; N, 13.95\%. Found: C, $55.96 ; \mathrm{H}, 3.46 ; \mathrm{N}, 14.09 \%$.

\subsection{Crystal structures determination and refinement}

The compounds 11,14 and 16 were obtained as single crystals by slow evaporation from its solutions (dichloromethanehexane; $2: 1$ ) to afford the pure compound at room temperature. Data were collected on a Bruker APEX-II D8 Venture area diffractometer, equipped with graphite monochromatic Mo $K \alpha$ radiation, $\lambda=0.71073 \AA$ at 293 (2) K. Cell refinement and data reduction were carried out by Bruker SAINT. SHELXT $^{23,24}$ was used to solve the structure. The final refinement was carried out by full-matrix least-squares techniques with anisotropic thermal data for non-hydrogen atoms on F. CCDC 1456403, 1468844 and 1456418 contain the supplementary crystallographic data for this compounds 11,14 and 16, respectively and can be obtained free of charge from the Cambridge Crystallographic Data Center via www.ccdc.cam. ac.uk/data_request/cif.

\subsection{Computational details}

The quantum chemical calculations were performed at the DFT/B3LYP level of theory and using the built in $6-31 \mathrm{G}(\mathrm{d}, \mathrm{p})$ basis set as in Gaussian 03 software. ${ }^{25}$ The input structures were taken from the crystallographic information files (CIFs) obtained from the X-ray single crystal measurements, which are reported here for the first time. The optimizations followed by frequency calculations at the optimized structures gave no imaginary frequency modes. In addition, the NMR chemical shifts and the UV-Vis electronic spectral bands were computed using the GIAO, ${ }^{26,27}$ and Time Dependent-DFT (TD-DFT) methods, ${ }^{28-30}$ respectively. The calculations were performed both in the gas phase and in presence of different solvents. The effects of solvent on the electronic spectra as well as the NMR chemical shifts were computed using solvent environment of the Polarizable Continuum Model (PCM). Relative chemical shifts are estimated by using corresponding 


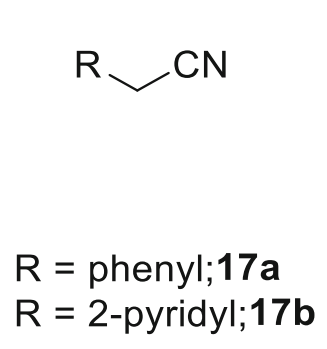

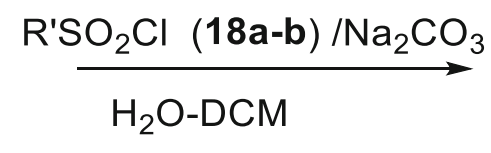

$$
\begin{aligned}
& \mathrm{R}=\text { phenyl; } 8 \\
& \mathrm{R}=2 \text {-pyridyl } ; 9
\end{aligned}
$$<smiles>[R][Sb]ON=C([R])C#N</smiles>

$$
\begin{aligned}
& R=\text { phenyl; R' = 4-methylphenyl; } 11 \\
& R=\text { phenyl; } R^{\prime}=2 \text {-naphthyl } 14 \\
& \text { R' }^{\prime}=2-\text {-Pyridyl; R' = 4-methylphenyl; } 16
\end{aligned}
$$

Scheme 1. Synthesis of oxyma sulfonate esters.

TMS shielding calculated in advance at the same theoretical level as the reference. GaussSum $2.2^{31}$ was utilized to analyze the electronic spectra of the studied compounds. Moreover, the electronic properties affecting the nonlinear optical (NLO) properties of the studied systems were computed as obtained from the frequency calculations.

The natural bond orbital (NBO) calculations were performed using NBO 3.1 program as implemented in the Gaussian 03W package at the DFT/B3LYP level in order to understand various intramolecular charge transfer interactions between the filled orbitals of one subsystem and vacant orbitals of another subsystem, which is a measure of the intermolecular delocalization or hyper-conjugation. ${ }^{32,33}$

\section{Results and Discussion}

\subsection{Synthesis of oxyma sulfonate}

The two oxyma 8 and $\mathbf{9}$ were prepared from their aryl nitrile derivatives $\mathbf{1 7 a}$, b following the reported method, ${ }^{19}$ and then reacted with the sulphonyl chloride derivatives 18a, $\mathbf{b}$ using the modified two-phase method (DCM- $\mathrm{H}_{2} \mathrm{O}$ ) to afford the sulfonate esters 11, 14 and 16 (Scheme 1) in excellent yields and purities as observed from their spectral data.

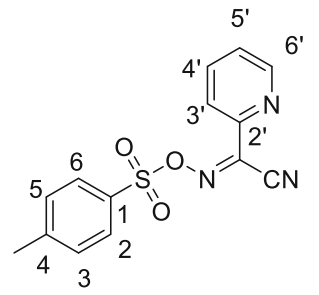

The ${ }^{1} \mathrm{H}$ NMR of $N$-(tosyloxy)picolinimidoyl cyanide 16 as a prototype showed a singlet peak at $\delta 2.46$ related to $\mathrm{CH}_{3}$ group, multiplet peak at $\delta 7.39-7.47$ corresponding to the three protons $\left(\mathrm{H} 3, \mathrm{H} 5, \mathrm{H} 5{ }^{\prime}\right)$, multiplet peak at $\delta 7.78-7.95$ corresponding to the four protons (H3',H4',H2 and H6), and doublet peak at $\delta 8.72$ corresponding to the H6'. ${ }^{13} \mathrm{C}$ NMR of $\mathbf{1 6}$ showed carbon signal peaks at $\delta 21.9\left(\mathrm{CH}_{3}\right), 107.4(\mathrm{CN}), 121.7\left(\mathrm{C}^{\prime}{ }^{\prime}\right), 126.9$ (C5'), 129.3 (C2'), 130.2(C6), 130.9(C3,5), 137.3(C4'),
140.1(C4), 146.8(C1-SO $\left.{ }_{2}\right), 146.9(\mathrm{C}=\mathrm{N}$, Oxime $)$, and 150.4(C2').

\subsection{X-ray crystallography}

Figure 4 presents the ORTEP diagrams of the compounds 11, 14 and 16. Displacement ellipsoids are plotted at the $40 \%$ probability level for non-H atoms. The crystallographic data and refinement information are summarized in Table 1. The asymmetric units contain one independent molecule as shown in Figure 4. All the bond lengths and angles are within normal ranges. ${ }^{34}$

\subsection{DFT studies}

3.3a Structure and electronic properties: The calculated geometries using B3LYP method drawn using Chemcraft software ${ }^{35}$ are shown in Figure 5. The overlay of the calculated and experimental X-ray structures indicated that the optimized molecular structures agreed well with the experimental results. Based on the calculated correlation coefficients $\left(\mathrm{R}^{2}\right)$ shown in Table $\mathrm{S} 1$ (Supplementary Information), the bond distances and angles obtained from the present calculations showed good correlations with the experimental data. The $\mathrm{R}^{2}$ values for the bond distances and angles are in the range of 0.9886-0.9969 (Table S1, Supplementary Information).

The charge distribution has a direct relation to the polarity of the compound since the compounds have almost similar structure patterns. The natural bond orbital (NBO) calculations were used to predict the natural atomic charges $\left(\mathrm{Q}_{\mathrm{NAC}}\right)$ at different atomic sites. The results of the natural atomic charges are given in Table 2. For all compounds, the three sulfonate O-atoms have the highest negative charge where the two free $\mathrm{O}$ atoms are more negative than the third one. It is the least negative in case of the pyridine derivative. The Sulfur atom is electropositive in all the studied compounds where the $\mathrm{Q}_{\mathrm{NAC}}$ is in the range 2.3910-2.3941e. The Hatoms are also electropositive. In contrast, all C-atoms 


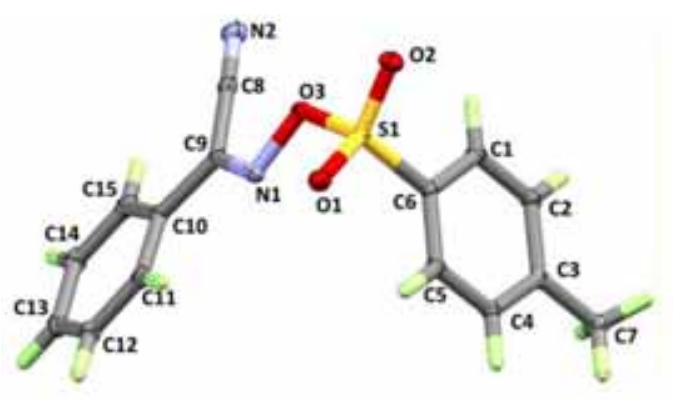

11

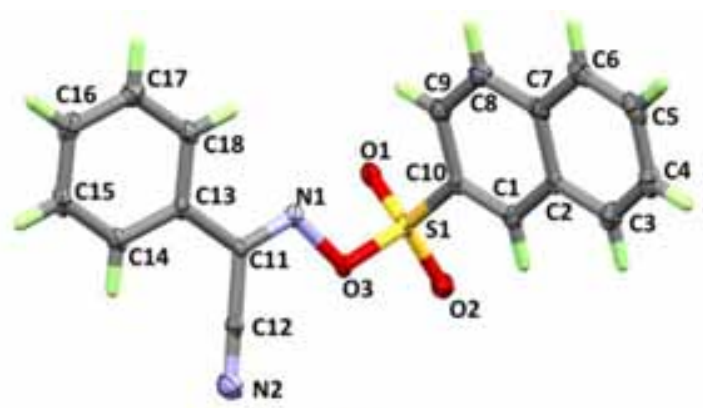

14

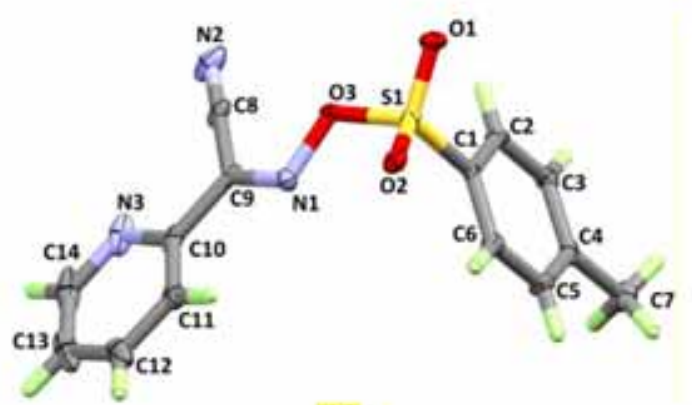

16

Figure 4. ORTEP diagrams of the 11, 14 and 16. Displacement ellipsoids are plotted at the $50 \%$ probability level for non-H atoms.

are electronegative except those attached to higher electronegative atoms such as nitrogen. The nitrile group $(\mathrm{C} \equiv \mathrm{N})$ nitrogen is richer in electrons than that for the $\mathrm{C}=\mathrm{N}$. In 16, the most electronegative $\mathrm{N}$-atom is the pyridine ring $\mathrm{N}$-site. In this regard, a comparison between the calculated dipole moments of the studied compounds revealed that the dipole moment values were calculated to be $7.7231,7.5512$, and 8.7468 Debye for $\mathbf{1 1}, \mathbf{1 4}$ and 16, respectively. It is clear that the presence of one more heteroatom $(\mathrm{N})$ in the case of $\mathbf{1 6}$ leads to more polar structure than the others.

Map of the electron densities over the molecular electrostatic potential is a useful picture for predicting the electrophilic and nucleophilic region in the molecular systems. In these maps, the red regions are usually characterized by high electron densities and susceptible to be attacked by an electrophile. The dark blue regions are the most favored sites to be attacked by nucleophile as it is considered as electron poor regions. The maps of the molecular electrostatic potential (MEP) were drawn using Gauss View software and shown in Figure 6. For all the studied system, the $\mathrm{N}$ and $\mathrm{O}$-atom of the nitrile and sulfonate groups, respectively, are the most reactive to the attack of electrophile. It is clear that $\mathbf{1 6}$ has an electron-rich region around the $\mathrm{N}$-atoms of the nitrile and pyridine rings. As a result, we could predict that this compound could act as good ligand in coordination chemistry than the others. The coordination of the metal ion as electrophile to these atomic sites of $\mathbf{1 6}$ is more favored over the others due to chelate effect. Dark blue regions around the $\mathrm{S}$-atom of the sulfonate reveal the electron poor character of this atomic site in all compounds.

3.3b Frontiermolecularorbitals: The frontier molecular orbitals HOMO and LUMO refer to the highest occupied and lowest unoccupied molecular orbitals, respectively. Their energies are important as they reflect the ability of the compound to give or take electrons (Table 3). The order of compounds according to HOMO energy is $14>11>16$. Hence, compound 14 is considered the most reactive compound towards electron donation. In contrast, 16 has the lowest energy LUMO orbital, and as a result is considered the best electron acceptor. In presence of solvent, all the HOMO levels are destabilized. The maximum destabilization occurred for 11. On the other hand, all the LUMO levels are stabilized where the maximum stabilization occur for $\mathbf{1 6}$. The difference in energy between HOMO and LUMO is the lowest amount of energy required for the electronic transition. Theoretically, the lowest transition energy is calculated to be 4.5294, 4.1451 and $4.6866 \mathrm{eV}$, for compounds 11,14 and 16, respectively in the gas phase. In presence of acetonitrile as solvent, the electronic transitions become easier and require a lower amount of energy. Among all the studied compounds, $\mathbf{1 4}$ has the lowest transition energy either in the gas phase or solution, in agreement with the fact that the presence of more 
Table 1. Crystal data for 11, 14 and $\mathbf{1 6 .}$

\begin{tabular}{|c|c|c|c|}
\hline & 11 & 14 & 16 \\
\hline \multicolumn{4}{|l|}{ Crystal data } \\
\hline Chemical formula & $\mathrm{C}_{15} \mathrm{H}_{12} \mathrm{~N}_{2} \mathrm{O}_{3} \mathrm{~S}$ & $\mathrm{C}_{18} \mathrm{H}_{12} \mathrm{~N}_{2} \mathrm{O}_{3} \mathrm{~S}$ & $\mathrm{C}_{14} \mathrm{H}_{11} \mathrm{~N}_{3} \mathrm{O}_{3} \mathrm{~S}$ \\
\hline $\mathrm{Mr}$ & 300.33 & 336.36 & 301.32 \\
\hline $\begin{array}{l}\text { Crystal system, space } \\
\text { group }\end{array}$ & Triclinic, $P-1$ & Triclinic, $P-1$ & Triclinic, $P-1$ \\
\hline Temperature (K) & 100 & 100 & 100 \\
\hline$a, b, c(\AA)$ & $\begin{array}{c}5.4641(3) \\
8.1232(5) \\
15.8195(9)\end{array}$ & $\begin{array}{l}7.4962(9) \\
7.4973(9) \\
14.0427(16)\end{array}$ & $\begin{array}{l}5.2075(6), \\
8.0975(10), \\
16.426(2)\end{array}$ \\
\hline$\alpha, \beta, \gamma\left({ }^{\circ}\right)$ & $\begin{array}{c}100.840(2) \\
98.332(2) \\
97.180(2)\end{array}$ & $\begin{array}{c}87.459(4) \\
77.948(4) \\
80.483(4)\end{array}$ & $\begin{array}{c}90.911(5) \\
98.825(5) \\
97.860(5)\end{array}$ \\
\hline$V\left(\AA^{3}\right)$ & $673.93(7)$ & $761.16(16)$ & $677.52(14)$ \\
\hline$Z$ & 2 & 2 & 2 \\
\hline Radiation type & Mo $K \alpha$ & Mo $K \alpha$ & Mo $K \alpha$ \\
\hline$\mu\left(\mathrm{mm}^{-1}\right)$ & 0.25 & 0.23 & 0.25 \\
\hline Crystal size (mm) & $\begin{array}{l}0.48 \times 0.27 \times \\
0.14\end{array}$ & $\begin{array}{l}0.36 \times 0.21 \times \\
0.15\end{array}$ & $\begin{array}{l}0.37 \times 0.19 \times \\
0.06\end{array}$ \\
\hline \multicolumn{4}{|l|}{ Data collection } \\
\hline Tmin, Tmax & $0.889,0.965$ & $0.921,0.966$ & $0.913,0.984$ \\
\hline $\begin{array}{l}\text { No. of measured, } \\
\text { independent and } \\
\text { observed }[\mathrm{I}>2 \sigma(\mathrm{I})] \\
\text { reflections }\end{array}$ & $\begin{array}{l}12941,3096, \\
2639\end{array}$ & $\begin{array}{l}9292,3280 \\
2487\end{array}$ & $\begin{array}{l}7960,3082 \\
2076\end{array}$ \\
\hline $\begin{array}{l}\mathrm{R}_{\text {int }} \\
\text { Refinement }\end{array}$ & 0.045 & 0.050 & 0.082 \\
\hline $\begin{array}{l}\mathrm{R}\left[F^{2}>\right. \\
\left.2 \sigma\left(F^{2}\right)\right], \operatorname{wR}\left(F^{2}\right), \mathrm{S}\end{array}$ & $\begin{array}{l}0.038,0.095, \\
1.04\end{array}$ & $\begin{array}{l}0.046,0.116 \\
1.03\end{array}$ & $\begin{array}{l}0.059,0.143, \\
1.01\end{array}$ \\
\hline No. of reflections & 3096 & 3280 & 3082 \\
\hline No. of $\mathrm{p}$ & 191 & 217 & 191 \\
\hline No. of restraints & 0 & 0 & 0 \\
\hline $\begin{array}{l}\Delta \rho_{\max }, \Delta \rho_{\min }\left(\mathrm{e}^{-3}\right) \\
\text { CCDC No. }\end{array}$ & $\begin{array}{l}0.43,-0.42 \\
\mathbf{1 4 5 6 4 0 3}\end{array}$ & $\begin{array}{l}0.44,-0.42 \\
\mathbf{1 4 6 8 8 4 4}\end{array}$ & $\begin{array}{l}0.47,-0.44 \\
\mathbf{1 4 5 6 4 1 8}\end{array}$ \\
\hline
\end{tabular}

conjugated $\pi$-system in the compound lowers the energy gap between the HOMO and LUMO levels.

\subsection{UV-Vis electronic absorption spectra}

The experimentally measured UV-Vis electronic absorption spectra of the studied compounds in different solvents are shown in Figure S4 (Supplementary Information). All the studied compounds have two common transition bands. We noted a significant hyperchromic effect by changing the solvent from $\mathrm{ACN}$ to methanol to DCM to DMF. In contrast, changing the solvent showed very little effect on the $\lambda_{\max }$ values indicating that the solvent change exerts a very little effect on the energies of the molecular orbitals included in these transitions. From this point of view, we decided to perform TDDFT calculations on one of these solvents to assign the obtained electronic transition bands. The maximum absorption wavelengths $\left(\lambda_{\max }\right)$ of the experimentally observed transition bands and the calculated $\lambda_{\max }$ values together with their oscillator strengths $\left(f_{\text {osc }}\right)$ based on the TD-DFT calculations are given in Table 4.

The assignment of these electronic transition bands is given in the molecular orbital diagram shown in Figures 7 and S5-6 (Supplementary Information). For 14, these two absorption bands are observed at 231 and 281 $\mathrm{nm}$. The TD-DFT calculations predicted these bands at $235.6 \mathrm{~nm}\left(\mathrm{f}_{\mathrm{osc}}=0.029\right)$ and $279.9 \mathrm{~nm}\left(\mathrm{f}_{\mathrm{osc}}=0.051\right)$, respectively in the gas phase. In presence of acetonitrile as solvent, the $\lambda_{\max }$ of the longer wavelength band showed almost no variation but some decrease in its absorption intensity is noted. In contrast, hypsochromic shift and increase in the absorption intensity occurred for the shorter $\lambda_{\max }$ band with increasing solvent polarity from the gas phase to acetonitrile. The assignments of the electronic spectra shown in these figures revealed the higher energy transitions observed for compound $\mathbf{1 6}$ where the two bands were observed at shorter $\lambda_{\max }$ than 


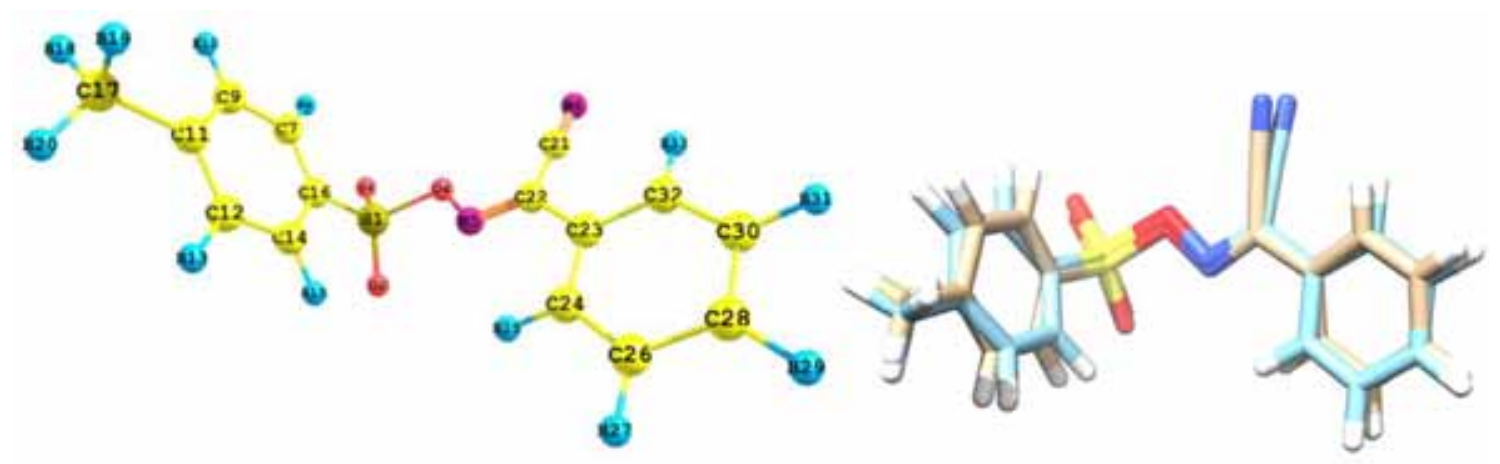

11
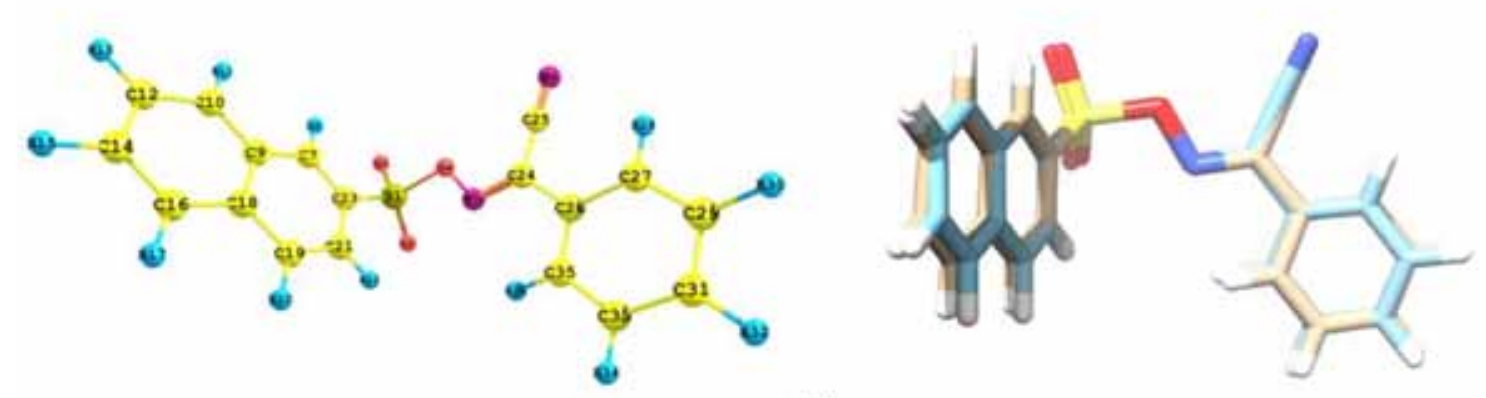

14
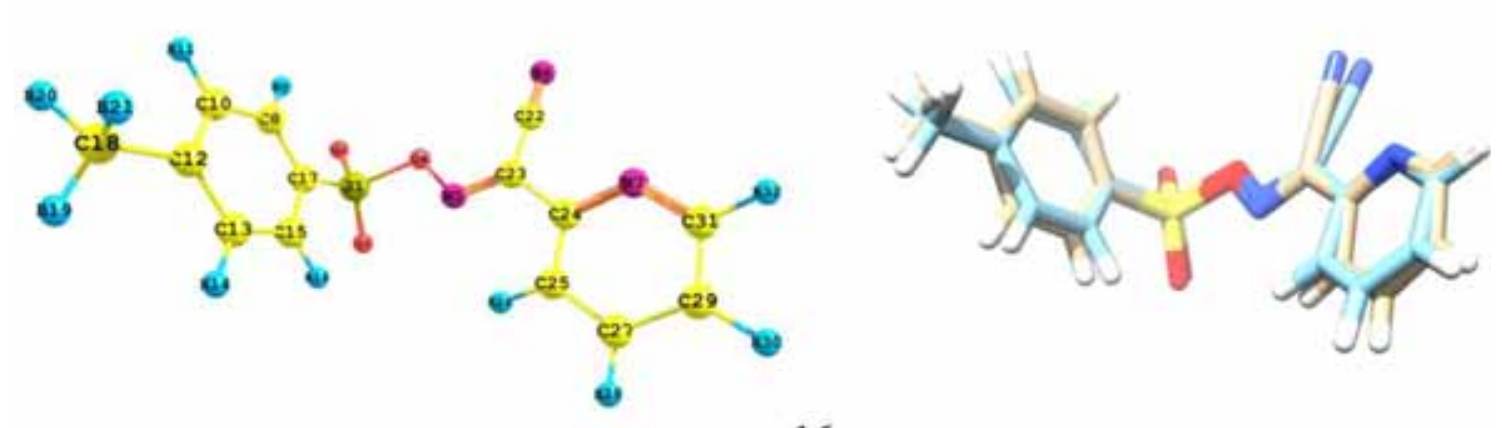

16

Figure 5. The optimized molecular structures of the studied compounds (left) and structure overlay between the calculated and X-ray single crystal structure (right).

the others, both experimentally and theoretically. These two bands were assigned to be mainly among molecular orbital with higher energy differences than those occurred in $\mathbf{1 4 .}$

\subsection{NMR spectra}

The nuclear magnetic resonance (NMR) chemical shifts were calculated using GIAO method in the gas phase and in the solution in order to match the results with those obtained experimentally. The calculated and experimental chemical shifts of the studied compounds are given in Table S2 (Supplementary Information). Correlations between the experimental and calculated ${ }^{1} \mathrm{H}$ and ${ }^{13} \mathrm{C}$-NMR chemical shifts were performed and the correlation coefficients are given in the same table. For compound 14, the correlation is moderate in the gas phase (0.7712-0.7669) and generally improved (0.8114-0.8861) when solvent effects were considered. For the rest of the compounds, the correlation coefficients are high indicating the good correlations between the calculated and experimental data. It is worth noting that the presented calculation gave better correlations with the experimental data for protons than carbon. Usually, the opposite of this was common in literature.

3.5a Nonlinearoptical(NLO) properties: Non-linear optical (NLO) effects occur when an intense beam of light such as laser interact nonlinearly with a material 
Table 2. The calculated natural charges of the studied compounds.

\begin{tabular}{|c|c|c|c|c|c|}
\hline \multicolumn{2}{|r|}{11} & \multicolumn{2}{|r|}{14} & \multicolumn{2}{|r|}{16} \\
\hline Atom & $\mathrm{Q}_{\mathrm{NAC}}$ & Atom & $\mathrm{Q}_{\mathrm{NAC}}$ & Atom & $\mathrm{Q}_{\mathrm{NAC}}$ \\
\hline & 2.3937 & S1 & 2.3941 & S1 & 2.39 \\
\hline & -0.8967 & & & $\mathrm{O} 2$ & -0.89 \\
\hline 3 & -0.900 & $\mathrm{O} 3$ & -0.90 & $\mathrm{O} 3$ & \\
\hline & -0.5 & $\mathrm{O} 4$ & -0.5 & $\mathrm{O} 4$ & \\
\hline & -0.09 & N5 & -0.0 & N5 & -0.0905 \\
\hline & -0.25 & 6 & -0.2 & N6 & -0.24 \\
\hline & -0.19 & C7 & -0.1 & N7 & -0 . \\
\hline & & & & & -0.1 \\
\hline & -0.228 & & -0.0 & H9 & \\
\hline 10 & & 10 & -0.1 & C10 & -0.2280 \\
\hline 11 & & & & & \\
\hline 12 & -0.2 ? & 12 & -0.2 & & \\
\hline 13 & 0.24 & 13 & & C13 & -0.2 \\
\hline 14 & -0.1 & & -0 . & & \\
\hline 15 & & & & & \\
\hline 16 & -0.3 & & -0 . & & \\
\hline 17 & -0.705 & H17 & & $\mathrm{C} 17$ & -0 \\
\hline I18 & & & -0.0 & $\mathrm{C} 18$ & -0.7 \\
\hline H19 & & C19 & -0.2 & & 0.2482 \\
\hline & & & & & \\
\hline 21 & 0.2 & 21 & -0.2 & $\mathrm{H} 2$ & \\
\hline $\mathrm{C} 22$ & & & & & \\
\hline $\mathrm{C} 23$ & -0.08 & $\mathrm{C} 23$ & -0.3 & $\mathrm{C} 2$ & 0.1119 \\
\hline 24 & -0.19 & & & $\mathrm{C} 24$ & \\
\hline 25 & & $\mathrm{C} 25$ & & $\mathrm{C} 25$ & -0.2 \\
\hline 26 & -0.23 & C26 & -0.0 & H26 & \\
\hline $\mathrm{H} 27$ & & $\mathrm{C} 27$ & -0.20 & $\mathrm{C} 27$ & -0.2007 \\
\hline $\mathrm{C} 28$ & -0.2173 & $\mathrm{H} 28$ & & $\mathrm{H} 28$ & \\
\hline H29 & & & -0.2 & C29 & \\
\hline$C_{3}$ & -0.23 & & & H30 & \\
\hline H31 & 0.248 & C31 & -0.2 & & 0.0268 \\
\hline C32 & -0.2083 & H32 & 0.2456 & H32 & 0.2356 \\
\hline H33 & 0.2557 & C33 & -0.2319 & & \\
\hline & & & & & \\
\hline & & C 35 & -0.19 & & \\
\hline & & H36 & 0.25 & & \\
\hline
\end{tabular}

to produce new fields, altered in its propagation characteristics like frequency or amplitude, compared to the incident fields. ${ }^{36}$ NLO is a hot topic in chemistry and physics researches and it has many applications related to optical and electronic devices. ${ }^{37-40}$ Organic systems having donor-acceptor $\pi$-conjugation are of interest in the field of nonlinear optical (NLO) properties. The nature of substituent and steric hindrance affects the degree of $\pi$-conjugation of the substances and hence its hyperpolarizability will be affected. As a result, the NLO of compound could be improved by the proper selection of substituent. ${ }^{41}$

Quantum chemical calculations can play an important role in the understanding of the structure-property relationship, which could be assisted in designing novel
NLO materials. The components of polarizability $(\alpha)$ and hyperpolarizability $(\beta)$ were used to calculate the total polarizability $\left(\alpha_{\text {tot }}\right)$ and hyperpolarizability $\left(\beta_{\text {tot }}\right)$ using equations 1 and 2, respectively.

$$
\begin{aligned}
\alpha_{\mathrm{tot}}= & \frac{1}{3}\left(\alpha_{\mathrm{xx}}+\alpha_{\mathrm{yy}}+\alpha_{\mathrm{zz}}\right) \\
\beta_{t o t}= & \left(\beta_{x x x}+\beta_{x y y}+\beta_{x z z}\right)^{2}+\left(\beta_{y y y}+\beta_{y x x}+\beta_{y z z}\right)^{2} \\
& +\left(\beta_{z z z}+\beta_{z x x}+\beta_{z y y}\right)^{2}
\end{aligned}
$$

The high values of polarizability $(\alpha)$ and the first hyperpolarizability $(\beta)$ of the investigated molecules clearly reveal that they have nonlinear optical (NLO) behavior (Table 5). In comparison to urea $\left(\alpha_{\text {tot }}=25.8793\right.$ A.U and $\beta_{\text {tot }}=43.1140$ A.U), compounds 14, 16 and 11 have $\alpha_{\text {tot }}$ values higher by $9.05,7.44$ and 7.63 times and $\beta_{\text {tot }}$ values higher by $7.71,2.66$ and 5.83 times. The values of the total polarizability $\left(\alpha_{\text {tot }}\right)$ and hyper-polarizability $\left(\beta_{\text {tot }}\right)$ shown in Table 5 indicated that $\mathbf{1 4}$ could be the best candidate for nonlinear optical applications as it has the highest $\alpha_{\text {tot }}$ and $\beta_{\text {tot }}$ values compared to the others. The higher conjugation occurred in $\mathbf{1 4}$ due to the presence of naphthyl group could be the reason for such NLO enhancement.

3.5b Second order perturbation energy analyses: The analysis of the interaction energies between the filled natural bond orbitals (NBOs) and the empty ones shed light on the ease of electron delocalization among electron pairs in the studied systems. The interaction energies deduced from the NBO analyses were shown in Table S3 (Supplementary Information). The most important interactions occurred in the studied systems are $\pi \rightarrow \pi^{*}, \mathrm{n} \rightarrow \pi^{*}$ and $\mathrm{n} \rightarrow \sigma^{*}$ intramolecular charge transfer (ICT). Because all the studied molecules have conjugated $\pi$-system, so many $\pi \rightarrow \pi^{*}$ ICT interactions were occurred. For 14, the strongest $\pi \rightarrow \pi^{*}$ ICT interaction has $20.40 \mathrm{kcal} / \mathrm{mol}$ for the $\mathrm{BD}(2) \mathrm{C} 33-\mathrm{C} 35 \rightarrow$ BD*(2)C29-C31 charge transfer which is related to the phenyl ring $\pi$-system. Another ICT also have high stabilization energy $(20.08 \mathrm{kcal} / \mathrm{mol})$ takes place between one of the phenyl ring $\pi$-system as the donor $(\mathrm{BD}(2) \mathrm{C} 26-\mathrm{C} 27)$ and the $\mathrm{BD} *(2) \mathrm{N} 5-\mathrm{C} 24$ as acceptor. In the case of $\mathbf{1 6}$, the highest energy $\pi \rightarrow \pi^{*}$ ICT interaction $(28.14 \mathrm{kcal} / \mathrm{mol})$ occurred among the pyridine ring $\pi$-bonds $\left(\mathrm{BD}(2) \mathrm{C} 25-\mathrm{C} 27 \rightarrow \mathrm{BD}^{*}(2) \mathrm{N} 7-\right.$ C24) while the second highest one $(26.47 \mathrm{kcal} / \mathrm{mol})$ is $\mathrm{BD}(2) \mathrm{C} 12-\mathrm{C} 13 \rightarrow \mathrm{BD}^{*}(2) \mathrm{C} 15-\mathrm{C} 17$ for the p-tolyl group. The latter occurred in $\mathbf{1 1}$ with almost the same ICT interaction energy $(26.81 \mathrm{kcal} / \mathrm{mol})$. For all compounds, there is only one significant $n \rightarrow \pi^{*}$ ICT delocalization occurred from the second lone pair of $\mathrm{O} 4$ $(\mathrm{LP}(2) \mathrm{O} 4)$ to the $\pi^{*}$-empty $\mathrm{NBO}$ of the adjacent $\mathrm{N} 5=\mathrm{C}$ 


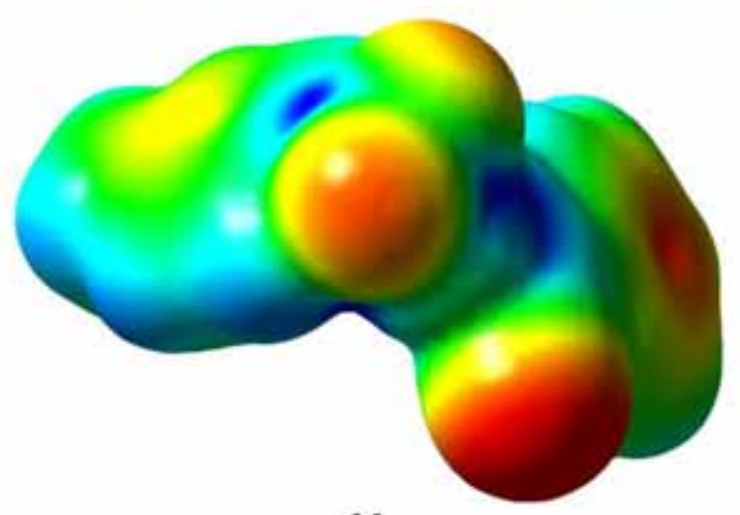

11

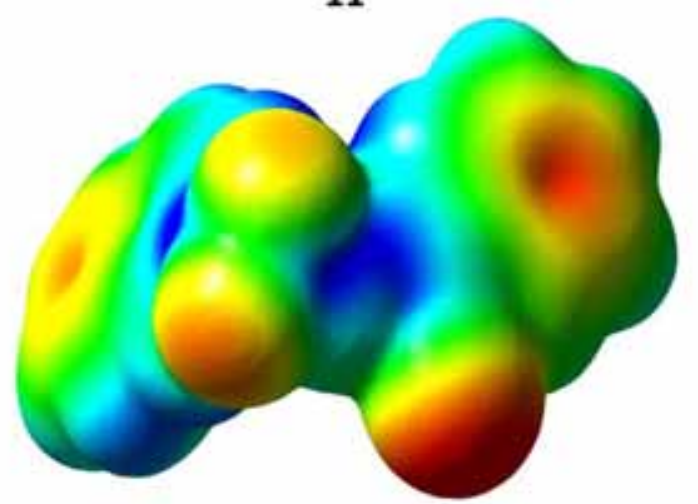

14

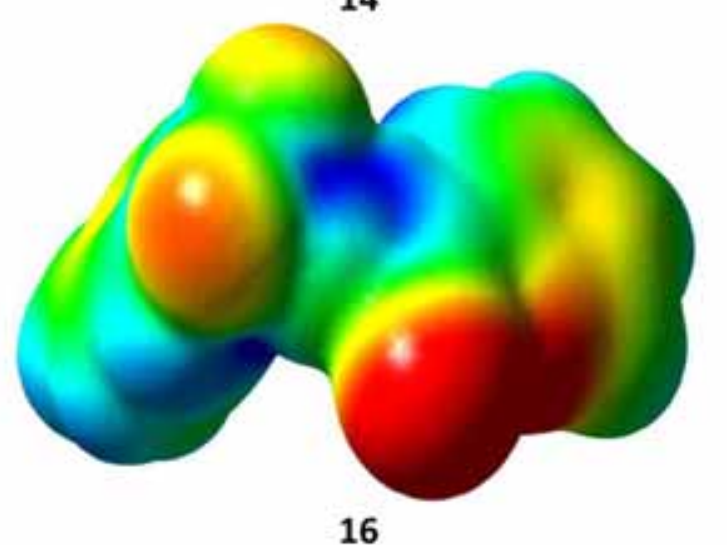

Figure 6. MEP maps of the studied compounds.

Table 3. The energies of the frontier molecular orbitals in the gas phase and in presence of acetonitrile as solvent.

\begin{tabular}{lrrrrrrrr}
\hline & \multicolumn{2}{c}{$\mathbf{1 1}$} & & \multicolumn{2}{c}{$\mathbf{1 4}$} & & \multicolumn{2}{c}{$\mathbf{1 6}$} \\
\cline { 2 - 3 } \cline { 8 - 9 } \cline { 8 - 9 } \cline { 8 - 9 } & \multicolumn{1}{c}{ gas } & ACN & & gas & ACN & & gas & ACN \\
\hline HOMO & -6.9411 & -6.8908 & & -6.5683 & -6.3275 & & -7.1950 & -7.1441 \\
LUMO & -2.4118 & -2.5154 & & -2.4232 & -2.5258 & & -2.5084 & -2.6384 \\
Gap & 4.5294 & 4.3754 & & 4.1451 & 3.8017 & & 4.6867 & 4.5057 \\
\hline
\end{tabular}


Table 4. The calculated and experimental $\lambda_{\max }(\mathrm{nm})$ and their oscillator strengths.

\begin{tabular}{lccl}
\hline$\left(\lambda_{\max }\right)$ exp. & $\left(\lambda_{\max }\right) \mathrm{calc}$ & $\mathrm{f}_{\mathrm{osc}}$ & \multicolumn{1}{c}{ Assignment } \\
\hline$\underline{\mathbf{1 1}}$ & & & \\
$\mathbf{2 2 7}$ & 229.6 & 0.344 & $\mathrm{H}-5 \rightarrow \mathrm{L}(15 \%), \mathrm{H}-1 \rightarrow \mathrm{L}+1(61 \%)$ \\
282 & 258.7 & 0.071 & $\mathrm{H}-4 \rightarrow \mathrm{L}(79 \%), \mathrm{H} \rightarrow \mathrm{L}+2(13 \%)$ \\
$\frac{\mathbf{1 4}}{231}$ & 233.8 & 0.919 & $\mathrm{H}-2 \rightarrow \mathrm{L}+1(27 \%), \mathrm{H}-1 \rightarrow \mathrm{L}+2(13 \%), \mathrm{H} \rightarrow \mathrm{L}+2(28 \%)$ \\
281 & 279.4 & 0.013 & $\mathrm{H}-2 \rightarrow \mathrm{L}+1(36 \%), \mathrm{H}-1 \rightarrow \mathrm{L}+1(15 \%), \mathrm{H} \rightarrow \mathrm{L}+2(41 \%)$ \\
$\underline{\mathbf{1 6}}$ & & & \\
219 & 223.7 & 0.152 & $\mathrm{H}-5 \rightarrow \mathrm{L}(36 \%), \mathrm{H}-1 \rightarrow \mathrm{L}+1(17 \%), \mathrm{H} \rightarrow \mathrm{L}+2(11 \%)$ \\
\hline
\end{tabular}
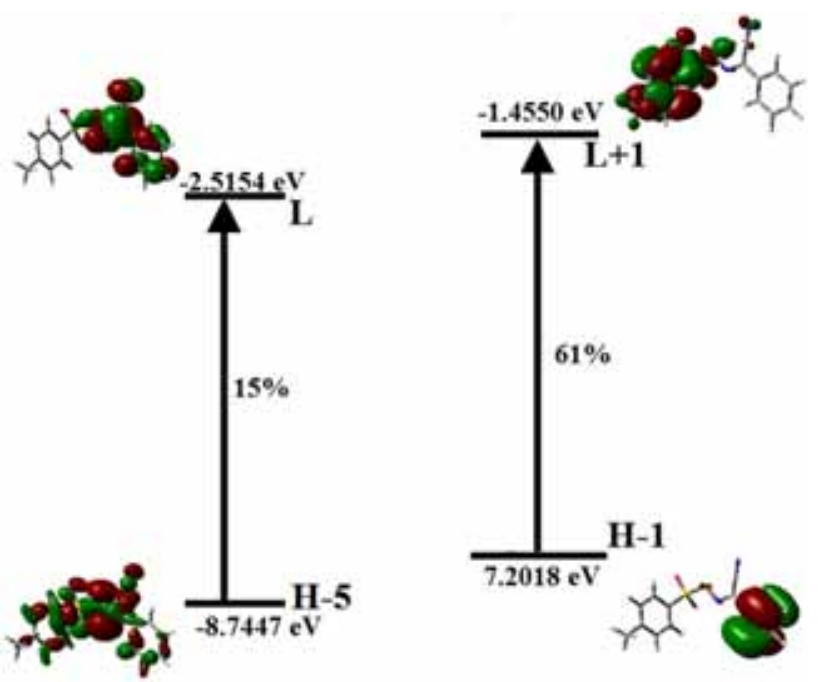

$227 \mathrm{~nm}$

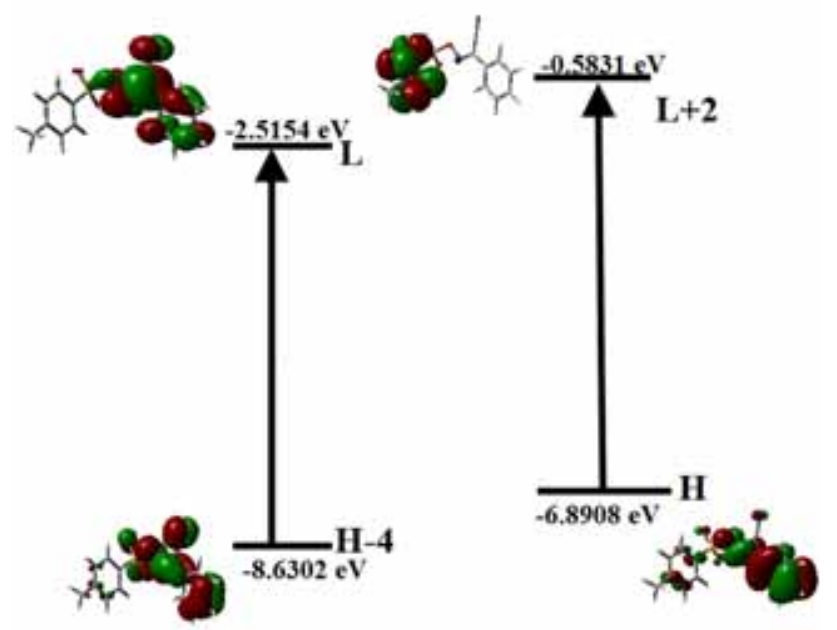

$282 \mathrm{~nm}$

Figure 7. The origin of the most important spectral bands of 11.

bond. The stabilization energies of these ICT interactions are $14.94,18.43$ and $15.62 \mathrm{kcal} / \mathrm{mol}$ for $\mathbf{1 1}, \mathbf{1 4}$ and $\mathbf{1 6}$, respectively. It is the maximum for $\mathbf{1 4}$. In the two compounds having the p-tolyl group, this ICT interaction has almost the same strength. Two factors could lead to such variations: (1) the O4 atom has more deviation by $1^{\circ}$ from the $\mathrm{C}=\mathrm{N} 5$ bond in $\mathbf{1 1}$ and $\mathbf{1 6}$ compared to $\mathbf{1 4}$ which will slightly weaken $\mathrm{LP}(2) \mathrm{O} 4 \rightarrow \mathrm{C}=\mathrm{N}$; (2) the electronic factor where the naphthyl ring conjugated $\pi$-system could be a better electron donor to the sulphonate moiety than the p-tolyl group, this will make the O4-atom more e-rich and more ICT to the neighboring $\mathrm{C}=\mathrm{N}$ bond will take place for $\mathbf{1 4}$ than the others. All the studied compounds have common features of $n \rightarrow \sigma^{*}$ ICT interactions, all have 10 of these interactions except $\mathbf{1 6}$ has one more $\mathrm{n} \rightarrow \sigma^{*}$ ICT from $\mathrm{LP}(1) \mathrm{N} 7 \rightarrow \mathrm{BD}^{*}(1) \mathrm{C} 24-\mathrm{C} 25(10.28 \mathrm{kcal} / \mathrm{mol})$ due to the replacement of the phenyl by pyridyl one. The highest of these interactions occurred from $\mathrm{LP}(3) \mathrm{O} 2$ and LP(3)O3 filled NBOs to the empty $\sigma^{*}$ NBOs of the S1-O4 bond. These interactions stabilized the system upto $38.96,38.21$ and $38.16 \mathrm{kcal} / \mathrm{mol}$ for $\mathbf{1 4 , 1 6}$ and $\mathbf{1 1}$, respectively.

3.5c Reactivity descriptors: Several reactivity descriptors such as ionization potential (I), electron affinity (A), chemical potential $(\mu)$, hardness $(\eta)$ as well as electrophilicity index $(\omega)$ were proposed for understanding various aspects of reactivity associated with chemical reactions. ${ }^{42-47}$ The definition of these parameters is given by Equations 1-5.

These chemical reactivity descriptors could be used for describing the different pharmacological and biological reactivity of compounds. Based on the molecular orbital calculations of the synthesized compounds, these reactivity descriptors are summarized and listed in Table 6. The results showed the order of the studied molecules according to chemical hardness is $\mathbf{1 6}>\mathbf{1 1}>$ 14. Compound $\mathbf{1 6}$ has the highest chemical hardness as it has one more electronegative atom in its structure. Moreover, all compounds have negative chemical potential so are considered stable compounds. It is well-known that 
Table 5. The polarizability and hyperpolarizability components and their total values (A.U) of the studied compounds.

\begin{tabular}{lrrrlrrr}
\hline Parameter & \multicolumn{1}{c}{11} & \multicolumn{1}{c}{14} & \multicolumn{1}{c}{16} & & \multicolumn{1}{c}{11} & \multicolumn{1}{c}{14} & \multicolumn{1}{c}{16} \\
\hline$\alpha_{\mathrm{xx}}$ & 233.6056 & 285.5122 & 225.5522 & $\boldsymbol{\beta}_{\mathbf{x x x}}$ & 119.5136 & 94.6122 & -81.4442 \\
$\alpha_{\mathrm{xy}}$ & -15.2611 & -3.9882 & -13.3882 & $\boldsymbol{\beta}_{\mathbf{x x y}}-166.5150$ & 233.0252 & -26.0682 \\
$\alpha_{\mathrm{yy}}$ & 197.1262 & 222.3290 & 190.7274 & $\boldsymbol{\beta}_{\mathbf{x y y}}$ & 47.1599 & -62.4914 & -38.3951 \\
$\alpha_{\mathrm{xz}}$ & 3.6825 & -25.3824 & 5.2904 & $\boldsymbol{\beta}_{\mathbf{y y y}}$ & -11.1243 & 97.9542 & -55.7361 \\
$\alpha_{\mathrm{yz}}$ & -26.5293 & 27.5889 & -23.8767 & $\boldsymbol{\beta}_{\mathbf{x x z}}$ & 143.3713 & 116.2308 & 85.6555 \\
$\alpha_{\mathrm{zz}}$ & 161.8942 & 194.8585 & 161.1696 & $\boldsymbol{\beta}_{\mathbf{x y z}}-106.4500$ & -125.3100 & -93.1212 \\
& & & & $\boldsymbol{\beta}_{\mathbf{y y z}}$ & -41.5483 & 10.6334 & -58.7575 \\
& & & & $\boldsymbol{\beta}_{\mathbf{x z z}}$ & 0.6574 & -1.9668 & 13.2321 \\
& & & & $\boldsymbol{\beta}_{\mathbf{y z z}}$ & 35.2847 & -27.8183 & 47.2213 \\
$\alpha_{\text {tot }}$ & 197.5420 & 234.2332 & 192.4831 & $\boldsymbol{\beta}_{\mathbf{z z z}}$ & 19.9696 & 6.4433 & -3.4542 \\
\hline
\end{tabular}

Table 6. The quantum chemical reactivity parameters of compounds $\mathbf{1 2 , 1 4}$ and $\mathbf{1 6}$.

\begin{tabular}{lrrr}
\hline Parameter & 11 & 14 & \multicolumn{1}{c}{16} \\
\hline $\mathrm{I}=-\mathrm{E}_{\mathrm{HOMO}}$ & 6.9411 & 6.5683 & 7.1950 \\
$\mathrm{~A}=-\mathrm{E}_{\mathrm{LUMO}}$ & 2.4118 & 2.4232 & 2.5084 \\
$\eta=(\mathrm{I}-\mathrm{A}) / 2$ & 2.2647 & 2.0726 & 2.3433 \\
$\mu=-(\mathrm{I}+\mathrm{A}) / 2$ & -4.6764 & -4.4958 & -4.8517 \\
$\omega=\mu^{2} / 2 \eta$ & 4.8283 & 4.8760 & 5.0225 \\
\hline
\end{tabular}

the flow of electrons could take place from the molecule with the highest chemical potential. From this point of view, the ability of the studied compounds to electron flow from it will be the highest for 14. Moreover, the electrophilicity index of the studied compounds is in the order $16>14>11$. As a result, 16 has the highest electrophilicity index so it has higher electrophilic behavior compared to the others, ${ }^{48}$ in agreement with a large number of strong electronegative atoms in this compound compared to the others.

\section{Conclusions}

The modified two-phase method of synthesis (using dichloromethane and water) gave three oxyma sulfonate esters in high yields and purities compared to the onephase method (dichloromethane) in the presence of organic base triethylamine. The modified method is considered as an eco-friendly method without any contamination of trimethylamine, which was used in the previously reported method. The molecular structures of the three studied compounds were calculated and found to be agreeing with the X-ray structures. DFT calculations showed that the order of compounds according to polarity is $\mathbf{1 6}>\mathbf{1 1}>\mathbf{1 4}$. Analyses of the electronic spectra were made using the TD-DFT method and the molecular orbitals involved in these electronic transitions were discussed. NBO method was used to calculate the natural atomic charges and investigate the intramolecular charge transfer interactions occurred in the studied systems. Chemical reactivity studies showed that the most electrophilic compound is $\mathbf{1 6}$ and the order of the studied molecules according to chemical hardness is $\mathbf{1 6}>\mathbf{1 1}>\mathbf{1 4}$. According to the total polarizability $\left(\alpha_{\text {tot }}\right)$ and hyperpolarizability $\left(\beta_{\text {tot }}\right), \mathbf{1 4}$ could be the best candidate for nonlinear optical applications.

\section{Supplementary Information (SI)}

NMR and UV-Vis absorption spectra, Tables S1-S3 and Figures $\mathrm{S} 1-\mathrm{S} 7$ are given as supplementary information. For details see www.ias.ac.in/chemsci.

\section{Acknowledgements}

The authors extend their appreciation to the Deanship of Scientific Research at King Saud University for funding this work through research Group No. (RGP-234, Saudi Arabia).

\section{References}

1. Hangan A C, Turza A, Lianastan R, Sevastre B, Pàll E, Cetean S and Oprean L T S 2016 Synthesis, crystal structure and characterization of new biologically active $\mathrm{Cu}$ (II) complexes with ligand derived from $\mathrm{N}$ substituted sulfonamide J. Chem. Sci. 128815

2. Tan C, de Noronha R G, Devi N S, Jabbar A A, Kaluz S, Liu Y, Mooring S R, Nicolaou K C, Wang B and Van Meir E G 2011 Sulfonamides as a New Scaffold for Hypoxia Inducible Factor Pathway Inhibitors Bioorg. Med. Chem. Lett. 215528

3. Wilden J D, Geldeard L, Lee C C, Judd D B and Caddick S 2007 Trichlorophenol (TCP) sulfonate esters: A selective alternative to pentafluorophenol (PFP) esters and 
sulfonyl chlorides for the preparation of sulfonamides Chem. Commun. 1074

4. O'Connell J F and Rapoport H 19921-Benzenesulfonyland 1-p-toluenesulfonyl-3-methylimidazolium triflates: Efficient reagents for the preparation of arylsulfonamides and arylsulfonates J. Org. Chem. 57477

5. Caddick S, Wilden J D and Judd D B 2004 Direct Synthesis of Sulfonamides and Activated Sulfonate Esters from Sulfonic Acids J. Am. Chem. Soc. 1261024

6. Katritzky A R, Rodriguez-Garcia V and Nair S K 2004 A General and Efficient Synthesis of Sulfonylbenzotriazoles from $N$-Chlorobenzotriazole and Sulfinic Acid Salts J. Org. Chem. 691849

7. Yan L, Bertarelli D C G, Hayallah A M, Meyer H, Klotz K N and Muller C E 2006 A New Synthesis of Sulfonamides by Aminolysis of $p$ Receptor Antagonists J. Med. Chem. 494384

8. Palakurthy N B, Nadimpally K C, Dev D, Rana S and Mandal B 2013 Sulfonamide Synthesis via Oxyma-Osulfonates - Compatibility to Acid Sensitive Groups and Solid-Phase Peptide Synthesis Eur. J. Org. Chem. 2627

9. Kundu B, Shukla S and Shukla M 1994 Use of 1- $\beta$ naphthalenesulfonyloxy benzotriazole as coupling reagent in solid phase peptide synthesis Tetrahedron Lett. 359613

10. Khare S K, Singh G, Agarwal K C and Kundu B 1998 Use of $1-\beta$-Naphthalene sulfonyloxybenzotriazole as Coupling Reagent for Peptide Synthesis in the Presence of Fluorinated Alcohols as Cosolvent Protein Pept. Lett. 5 171

11. Devedas B, Kundu B, Srivastava A and Mathur K B 1993 6-Nitro-1- $\beta$-Naphthalenesulfonyloxybenzotriazole: A Novel Coupling Reagent For Peptide Synthesis Tetrahedron Lett. 346455

12. Carpino L A, El-Faham A and Albericio F 1994 Use of Onium Salt-Based Coupling Reagents in Peptide Synthesis Tetrahedron Lett. 352279

13. Han Y, Albericio F and Barany G 1997 Occurrence and Minimization of Cysteine Racemization during Stepwise Solid-Phase Peptide Synthesis J. Org. Chem. 624307

14. Carpino L A, Xia J, Zhang C and El-Faham A 2004 Organophosphorus and nitro-substituted sulfonate esters of 1-hydroxy-7-azabenzotriazole as highly efficient fastacting peptide coupling reagents J. Org. Chem. 6962

15. Carpino L A 19931-Hydroxy-7-azabenzotriazole: An efficient peptide coupling additive J. Am. Chem. Soc. 115 4397

16. Carpino L A, El-Faham A and Albericio F 1995 Efficiency in Peptide Coupling: 1-Hydroxy-7azabenzotriazole vs 3,4-Dihydro-3-hydroxy-4-oxo1,2,3-benzotriazine J. Org. Chem. 603561

17. Wehrstedt K D, Wandrey P A and Heitkamp D 2005 Explosive properties of 1-hydroxybenzotriazole $J$. Hazard. Mater. 1261

18. Subirós-Funosas R, Prohens R, Barbas R, El-Faham A and Albericio F 2009 Oxyma: An efficient additive for peptide synthesis to replace benzotriazole-based $\mathrm{HOBt}$ and HOAt with a lower risk of explosion Chem. Eur. J. 15 9394

19. Khattab Sh N 2010 Sulfonate Esters of 1Hydroxypyridin-2(1H)-one and Ethyl 2-Cyano-2(hydroxyimino)acetate (Oxyma) as Effective Peptide Coupling Reagents to Replace 1-Hydroxybenzotriazole and 1-Hydroxy-7-azabenzotriazole Chem. Pharm. Bull. 58501

20. El-Faham A, Elnakdy Y A, El Gazzar M S A, Abd El-Rahman M M and Khattab Sh N 2014 Synthesis, characterization and anti-proliferation activities of novel oximinosulfonate esters Chem. Pharm. Bull. 62373

21. Khattab Sh N, Subirós-Funosas R, El-Faham A and Albericio F 2012 Cyanoacetamide-based oxime carbonates: an efficient, simple alternative for the introduction of Fmoc with minimal dipeptide formation Tetrahedron 683056

22. Khattab Sh N, Subirós-Funosas R, El-Faham A and Albericio F 2012 Screening of NHydroxysuccinimide Chemistry Open 1147

23. Sheldrick G M Crystal structure refinement with SHELXL 2015 Acta Crystallogr. C 713

24. Sheldrick G M, SHELXTL-PC (Version 5.1) 1997 Siemens Analytical Instruments, Inc., Madison, WI

25. (a) Frisch M J and et al.,2004 Gaussian-03, Revision C.01, Gaussian, Inc., Wallingford, CT; (b) GaussView, 2007 Version 4.1, Dennington R II, T Keith, J Millam, Semichem Inc., Shawnee Mission, KS

26. Ditchfield R 1972 Molecular orbital theory of magnetic shielding and magnetic susceptibility J. Chem. Phys. 56 5688

27. Wolinski K, Hinton J F and Pulay P 1990 Efficient implementation of the gauge-independent atomic orbital method for NMR chemical shift calculations J. Am. Chem. Soc. 1128251

28. Petersilka M, Gossmann U J and Gross E K U 1996 Excitation Energies from Time-Dependent DensityFunctional Theory Phys. Rev. Lett. 761212

29. Bauernschmitt R and Ahlrichs R 1996 Treatment of electronic excitations within the adiabatic approximation of time dependent density functional theory Chem. Phys. Lett. 256454

30. Jamorski C, Casida M E and Salahub D R 1996 Dynamic polarizabilities and excitation spectra from a molecular implementation of time-dependent density-functional response theory: $\mathrm{N}_{2}$ as a case study J. Chem. Phys. 104 5134

31. O'Boyle N M, Tenderholt A L and Langner $\mathrm{K} \mathrm{M}$ 2008 cclib: A library for package-independent computational chemistry algorithms J. Comput. Chem. 29 839

32. Kisel V M, Kostyrko E O and Kovtunenko V A 2002 Synthesis and Biological Properties of Isoquinolines Spirofused with Carbocycles and Heterocycles at Position 4 Chem. Heterocycl. Compd. $\mathbf{3 8} 1295$

33. Jarrahpour A, Ebtahimi E, De Clercq E, Sinou V, Latour C D, Bouktab L and Brunel J M 2011 Regio- and sterochemistry of the $[2+2]$-cycloaddition reaction between enones and alkenes. A DFT study Tetrahedron 67 8699

34. Allen F H, Kennard O, Watson D G, Brammer L, Orpen A G and Taylor R 1987 Tables of bond lengths determined by $X$-ray and neutron diffraction. Part 1 . Bond lengths in organic compounds Part. J. Chem. Soc. Perkins Trans. II 1

35. Zhurko G A and Zhurko D A 2005 Chemcraft: Lite Version Build 08 (Freeware, Available online: http://www. chemcraftprog.com) 
36. Sun $Y$ X, Hao Q L, Wei W X, Yu Z X, Lu L D, Wang $X$ and Wang Y S 2009 Experimental and density functional studies on 4-(3,4dihydroxy benzylideneamino)antipyrine, and 4-(2,3,4trihydroxybenzylideneamino)antipyrine $\mathrm{J}$. Mol. Str. Theochem. 90474

37. Andraud C, Brotin T, Garcia C, Pelle F, Goldner P, Bigot B and Collet A 1994 Theoretical and experimental investigations of the nonlinear optical properties of vanillin, polyenovanillin, and bisvanillin derivatives J. Am. Chem. Soc. 1162094

38. Geskin V M, Lambert C and Bredas J L 2003 Origin of High Second- and Third-Order Nonlinear Optical Response in Ammonio/BoratoDiphenylpolyene Zwitterions: the Remarkable Role of Polarized Aromatic Groups J. Am. Chem. Soc. 12515651

39. Nakano M, Fujita H, Takahata $M$ and Yamaguchi $K$ 2002 Theoretical Study on Second Hyperpolarizabilities of Phenylacetylene Dendrimer: Toward an Understanding of Structure-Property Relation in NLO Responses of Fractal Antenna Dendrimers J. Am. Chem. Soc. 1249648

40. Sajan D, Joe H, Jayakumar V S and Zaleski J 2006 Structural and electronic contributions to hyperpolarizability in methyl p-hydroxy benzoate J. Mol. Str. 78543

41. Mahanalingam K, Nethaji M and Das P K 1996 Second harmonic generation in push-pull ethylenes: Influence of chirality and hydrogen bonding J. Mol. Str. 378 177

42. Foresman J B, Frisch A E 1996 Exploring Chemistry with Electronic Structure Methods, second ed., Gaussian, Pittsburgh, PA.

43. Chang R 2001 Chemistry $7^{\text {th }}$ edn. (New York: McGrawHill)

44. Kosar B and Albayrak C 2011 Spectroscopic investigations and quantum chemical computational study of (E)-4-methoxy-2-[(p-tolylimino)methyl]phenol Spectrochim. Acta 78160

45. Koopmans T A 1993 Über die Zuordnung von Wellenfunktionen und Eigenwertenzu den Einzelnen Elektronen Eines Atoms Physica 104

46. Parr R G and Yang W 1989 Density-Functional Theory of Atoms and Molecules (New York: Oxford University Press)

47. Parr R G, Von Szentpàly L and Liu S B 1999 Electrophilicity index J. Am. Chem. Soc. 1211922

48. Singh R N, Kumar A, Tiwari R K, Rawat P and Gupta V P 2013 A combined experimental and quantum chemical (DFT and AIM) study on molecular structure, spectroscopic properties, NBO and multiple interaction analysis in a novel ethyl 4-[2-(carbamoyl)hydrazinylidene]-3,5dimethyl-1 $H$-pyrrole-2-carboxylate and its dimer $J$. Mol. Str. 1035427 